\title{
BolAÑo, EL ARTESANo
}

\author{
Gustavo Bueno-Rojas ${ }^{1}$ \\ Universidad Autónoma de Occidente, Colombia
}

\begin{abstract}
Resumen: La vida de Roberto Bolaño estuvo marcada, además de la gran pasión que tenía por la literatura, por la diversidad de oficios que desarrolló como inmigrante en Europa para subsistir. Ser un obrero, alguien que realiza un oficio puntual durante mucho tiempo, puede ayudarnos a entender por qué Bolaño pudo realizar una producción literaria tan abundante. En este artículo exploramos, a través de lo que plantea Richard Sennett sobre cómo un artesano logra perfeccionar su oficio, la manera en la que Bolaño concibió la escritura y perfeccionó su quehacer escritural.
\end{abstract}

Palabras clave: Bolaño; artesano; Sennett; oficio; escritura.

\section{Bolaño, the craftsman}

\begin{abstract}
Roberto Bolaño's life was marked, also his great passion for literature, to diversity of jobs he developed as an immigrant in Europe to survive. Being laborer, who make a punctual trade for a long time, can help us understand why Bolaño could make such an abundant literary production. In this article we explore, through Richard Sennett raises about how a craftsman manages to perfect his trade, the way in which Bolaño conceived the writing and perfected his scriptural work.

Key words: Bolaño; craftsman; Sennett; trade; writing.
\end{abstract}

El filósofo Richard Sennett asegura que el término "artesanía" designa "un impulso humano duradero y básico, el deseo de realizar bien una tarea, sin más" (12), y que el objetivo del Artesano no es más que el deseo de hacer bien algo, solo por hacerlo bien. Esta definición del filósofo estadounidense sobre el artesano y su quehacer me ha hecho pensar en Roberto Bolaño, no solo en su oficio de escritor, sino también en su manera de vivir.

Montaigne, cita Vila-Matas, (48) solía decir que la meta de la filosofía era enseñar a morir, pero con el tiempo rectificó y dijo que la verdadera meta de la filosofía era enseñar a vivir. Los escritores, sin

${ }^{1}$ Profesor y escritor. Licenciado en Literatura de la Universidad del Valle y Magíster en Escrituras Creativas del a Universidad Nacional. Correo electrónico: rojasbueno@gmail.com 


\section{Gustavo Bueno Rojas}

duda, nos dedicamos a este oficio con el objetivo de no desaparecer, de seguir existiendo, de perdurar y pasamos horas encontrando la mejor manera de hacerlo.

Bolaño, quien supo desde temprano que moriría joven, decidió consagrarse al milenario oficio de la escritura. Lo hizo especialmente en los últimos años de su vida con gran pasión, luchando contra la cuenta regresiva del reloj. Cuando pienso en él, en esos desvaríos insólitos pero gratificantes que da la imaginación, siempre vuelve la misma escena: un tipo sentado en una mesa de madera, vestido de negro, tecleando en una máquina de escribir letras que se convierten en palabras, luego en oraciones y en párrafos que dan forma a Ulises Lima, a Auxilio Lacouture, al desierto de Sonora y a Sensini. También veo cómo las hojas que antes eran blancas caen al piso de un cuarto escueto, en el que habitan el hombre, su máquina de escribir y un montón de libros en el que alcanzo a identificar La vida, instrucciones de uso, de Perec.

No sé por qué me he hecho a esa imagen de él, pero es el Bolaño que vive en mi memoria, tal vez porque su prosa, que es un frenesí que encarna la lucidez poética, me llegó siempre en desbandada. Quizás tiene que ver con la velocidad con la que afrontó la vida. La escritora mexicana Carmen Boullosa (419), recuerda a un Bolaño pendenciero en el DF, alterador del orden de las cosas, de la poesía, como un agitador de fiestas que se escapó del mundo literario mejicano para poder escribir, para hacer poesía.

Viajó a Europa no por la promesa de un cargo diplomático o para convertirse en corresponsal de algún medio de comunicación en París o Barcelona; se exilió con la única certeza que lo acompañó siempre, la de querer ser escritor. Esa convicción lo llevó a no dedicarse de lleno al ejercicio literario, lo convirtió en un vigilante nocturno en un campo de verano, en estibador en un muelle de carga y todo lo hizo con la vehemencia, la fascinación y la disciplina que le producía la literatura. Estas labores no hicieron más que reflejar la actitud de Bolaño para ver el mundo y al igual que un maestro artesano, se consagró al oficio en cuerpo y alma.

Sennett apunta que:

Todo buen artesano mantiene un diálogo entre unas prácticas concretas y el pensamiento; este diálogo evoluciona hasta convertirse en 
hábitos, los que establecen a su vez un ritmo entre la solución y el descubrimiento de problemas. La conexión entre la mano y la cabeza se advierte en dominios aparentemente tan distintos como la albañilería, la cocina, el diseño de un patio de recreo o la ejecución musical al violonchelo, pero todas estas prácticas pueden fracasar o no desarrollarse plenamente. No hay nada inevitable en lo tocante a la adquisición de una habilidad, de la misma manera en que no hay nada irreflexivamente mecánico en torno a la técnica misma. (Sennett p.32)

Esa conexión entre la mano y la cabeza que anota Sennett, se encarna en el oficio del escritor. La escritura, como la albañilería se aprende haciendo, y Bolaño lo tenía tan claro que su pasión desbordada por la lectura y la escritura lo llevó a producir un sinnúmero de notas, novelas no terminadas, que después de su muerte se publican y hacen que la presencia del autor de Los detectives salvajes sea la de alguien que parece estar vivo.

Bolaño descubrió en la práctica cotidiana del ejercicio escritural la perfección a la hora de contar sus historias, de explorar el lenguaje poético para encontrar su propia voz. Al igual que un orfebre, creador de joyas con hilos de plata, tejió su mundo con paciencia y al igual que un aprendiz que mira el trabajo de su maestro en el taller, leyó sin descanso y siguió a Nicanor Parra, a Perec, a Vila Matas y a muchos otros para entender cómo se hacían esas obras, es decir, observó por horas enteras a quienes tenían más experiencia para descubrir sus técnicas y aprenderlas para luego crear sus obras. De Perec aprendió la arquitectura, con Vila-Matas amplió su espectro literario y con Parra exploró la poesía para resucitar y entender que "poesía [es] entrar en el sueño como un buzo muerto en el ojo de Dios". (Bolaño, Los Perros Románticos 15).

Para Roberto Bolaño, escribió Rodrigo Fresán, "ser escritor no era una vocación, era un modo de ser, de vivir la vida" (Vila-Matas 48). Hace algunos años escribí unas crónicas sobre artesanos de Colombia, Los hijos de Hefesto. Cuando inicié el proyecto, iba con la firme idea de conocer la técnica para tejer o trabajar con barro o arcilla, madera, en fin, de conocer cuál era la labor de esos hombres y mujeres con los insumos que les proporcionaba el entorno en el que vivían. A medida que transcurrieron los viajes para visitar sus talleres y conversar con 
ellos, entendí que el material era solo un vehículo para representar su forma de ver el mundo, todos llevaban años perfeccionando el oficio heredado de sus padres y abuelos o aprendido por la necesidad de tener un medio de subsistencia.

Recuerdo a un artesano de Pasto en el departamento de Nariño, al sur occidente de Colombia, Gilberto Granja, dedicado a una técnica ancestral llamada Mopa mopa que consiste en preparar una resina vegetal producida por un arbusto que lleva este mismo nombre y crece silvestre en la región del piedemonte amazónico (Caquetá, Putumayo y Sucumbíos) que hoy en día se usa para decorar objetos de madera y que antiguamente los indígenas utilizaban para la construcción de elementos de cacerías y como adhesivo para pegar las plumas de los penachos ceremoniales. Recuerdo la imagen del maestro Granja sentado en la pequeña butaca haciendo su trabajo, envuelto por el silencio y enseñándome que lo más importante de su oficio era la paciencia y la dedicación y que los trabajos se terminan cuando se tienen que terminar. El Maestro Granja lleva más de cincuenta años dedicado a esa labor.

En los días en que lo visité y conversamos, se me hizo difícil no pensar en el oficio del escritor, mi oficio, en la paciencia y en la obstinación única que menciona Perec y que tuvo Bolaño y que aún tiene el artesano Granja, esa forma de obstinación que para los que escribimos se materializa en novelas, relatos o poesía, esa obstinación que depende de cada cuerpo, de cada mente, de cada forma de entender el mundo, que está expuesta en la conexión intrínseca entre el cerebro y la mano, que tiene como único fin la perfección. En el discurso de recepción del Rómulo Gallegos, Bolaño habla sobre las patrias del escritor y anota que puede ser su lengua o la biblioteca, pero aclara que solo hay un pasaporte para ese viaje:

Muchas pueden ser las patrias, se me ocurre ahora, pero uno solo el pasaporte, y ese pasaporte evidentemente es el de la calidad de la escritura. Que no significa escribir bien, porque eso lo puede hacer cualquiera, sino escribir maravillosamente bien, y ni siquiera eso, pues escribir maravillosamente bien también lo puede hacer cualquiera. ¿Entonces qué es una escritura de calidad? Pues lo que siempre ha sido: saber meter la cabeza en lo oscuro, saber saltar al vacío, saber que la literatura básicamente es un oficio peligroso. Correr por el borde del precipicio: a 
un lado el abismo sin fondo y al otro lado las caras que uno quiere, las sonrientes caras que uno quiere, y los libros, y los amigos, y la comida. $\mathrm{Y}$ aceptar esa evidencia aunque a veces nos pese más que la losa que cubre los restos de todos los escritores muertos. La literatura, como diría una folclórica andaluza, es un peligro. (Bolaño 38-39)

El mayor grado de jerarquía de un artesano es el de maestro y se alcanza con el tiempo. Según Sennett, "para producir un maestro carpintero o músico hacen falta diez mil horas de experiencia" (18). Bolaño no tuvo una vida extensa, pero sí muy intensa y no cabe duda que debió trascender esas horas que anota Sennett. El deber en ese grado de maestro para un artesano está en enseñar lo que sabe a gente más joven, que se denominan aprendices, especialmente para que el oficio no se pierda. Bolaño logró alcanzar ese grado, quizás, después de muerto, pero es indudable que hoy sus aprendices están dispersos por el mundo y que, como escribe Vila-Matas al recordar cuando le enviaba sus novelas antes de publicarlas para que les echara un último vistazo, "Bolaño vivía la vida de tal forma que nos enseñaba a escribir, como si estuviera diciéndonos que jamás hay que perder de vista que vivir y escribir no admite bromas, aunque uno sonría" (48-49).

\section{Referencias}

Bolaño, Roberto. "Discurso de Caracas". Entre paréntesis. Barcelona: Editorial Anagrama, 2004. Impreso.

Roberto Bolaño. Los perros románticos. Barcelona: Editorial Lumen, 2000. Impreso.

Vila-Matas, Enrique. "Un plato fuerte de la China destruida". Bolaño Salvaje. Ed. Edmundo Paz y Gustavo Faverón. Barcelona: Editorial Candaya, 2008. Impreso.

Sennett, Richard. El artesano. Trad. Marco Aurelio Galmarini. Barcelona: Anagrama, 2009. Impreso. 